Daniel Młocicki · Zdzisław Świderski · Catarina Eira

Jordi Miquel

\title{
An ultrastructural study of embryonic envelope formation in the anoplocephalid cestode Mosgovoyia ctenoides (Railliet, 1890) Beveridge, 1978
}

Published online: 14 April 2005

(C) Springer-Verlag 2005

\section{Parasitol Res (2005) 95:243-251}

The names of the authors Daniel Młocicki and Zdzisław Swiderski were misspelled in the printed version of the article. The correct spellings are shown here.

\section{References}

Świderski Z (1968) Electron-microscopy of embryonic envelope formation by the cestode Catenotaenia pusilla. Exp Parasitol 23:104-113

Świderski Z (1994) Origin, differentiation and ultrastructure of egg envelopes surrounding coracidia of Bothriocephalus clavibothrium. Acta Parasitol 39:73-81

Świderski Z (1996) Comparative studies on ultrastructure, homology and analogy of egg envelopes in trematodes and cestodes. Wiad Parazytol 42:81-93
Swiderski Z, Chomicz L (1994) Ultrastructure of the early embryos of the cestode Hymenolepis microstoma (Cyclophyllidea, Hymenolepididae). Proceedings of the 13th International Congress on Electron Microscopy, Paris, pp 1423-1424

Swiderski Z, Mackiewicz JS (2004) Ultrastructural studies on the cellular organisation of the coracidium of the cestode Bothriocephalus clavibothrium Ariola, 1899 (Pseudophyllidae, Bothriocephalidae). Acta Parasitol 49:116-139

Swiderski Z, Tkach VV (2002) Ultrastructure of embryonic development of Inermicapsifer madagascariensis (Cestoda, Anoplocephalidae) with emphasis on the cellular organisation of the infective eggs. Acta Parasitol 47:105-120

Swiderski Z, Ndiaye PI, Tkach V, Miquel J, Marchand B, Chomicz L, Sereda MJ (2001) Ultrastructural study of the embryonic development of the anoplocephalid cestode Anoplocephaloides dentata, an intestinal parasite of Arvicolidae rodents. I. Egg envelope formation. Acta Parasitol 46:171-185

The online version of the original article can be found at http:// dx.doi.org/10.1007/s00436-004-1276-4

D. Młocicki $(\square) \cdot Z$. Świderski

W. Stefanski Institute of Parasitology,

Polish Academy of Sciences, 51/55 Twarda Street,

00-818 Warsaw, Poland

E-mail: danmlo@twarda.pan.pl

Tel.: + 48-22-6978966

Fax: + 48-22-6206227

Z. Świderski

Department of General Biology and Parasitology,

Medical University of Warsaw, 5 Chałubińskiego Street,

02-004 Warsaw, Poland

C. Eira $\cdot$ J. Miquel

Laboratori de Parasitologia, Facultat de Farmàcia,

Universitat de Barcelona, Av. Joan XXIII s/n,

08028 Barcelona, Spain 